\title{
Editing a Paper from Submission to Publication
}

\author{
Amjad Kallel
}

\section{Keywords}

Scientific paper • Editing process • Editorial Manager system (EM) • Impact Factor

The research/data curried out by scientists and submitted for publication requires fastidious tasks through a long pathway until the day of its publication. The Editors are the hub of the process and have to handle the pressure of the authors - who want to see their work published in the shortest timemeanwhile without sacrificing quality and integrity of the journal. In addition to his concern about the scientific content in a paper (quality), the editor still has to carefully check and ensure the respect of publication ethics. Submission/Editing systems such as the Editorial Manager system (EM) is one of the tools used nowadays by journals helping them to handle several hundreds of submissions each year.

How to efficiently use and manipulate the different features of EM from initial submission until rendering the final decision (technical check and similarity report, targeting/inviting relevant reviewers, responding to authors queries, following up with Associate Editors and reviewers, etc.)?

On the other hand, the increase of the Impact Factor is the goal to achieve for the journal team, meanwhile it is the catalyst of the journal success and plays a key role to attract and gain interest of authors in term of number as well as quality. Nevertheless, for a newly launched journal, several approaches and actions have to be followed by the editorial board to promote the journal and increase its impacts among the scientific community and competitive journals.
This workshop intends to present/discuss the main steps for a successful editing process: What should be done and how it is done?

\section{Author Biography}

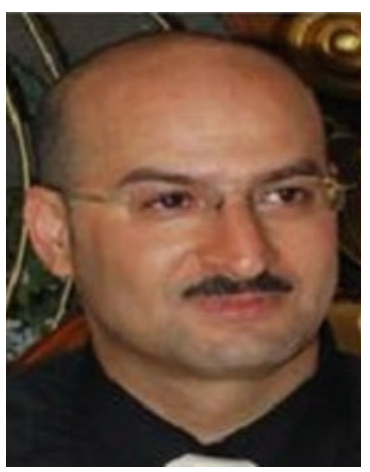

Dr. Amjad Kallel holds a B. Eng. in Georesources and Environment (1998) from the University of Sfax (Tunisia), an M.Sc. degree and a Ph.D. degree in Georesources and Environment (2004) from Hokkaido University (Japan). He joined Venture Business Laboratory (VBL) at Akita University, Japan (2005-2006) as a researcher focusing on refining and recycling technologies for the recovery of rare elements from natural and secondary sources. Back in Tunisia, he worked at the University of Gabes from 2006 to 2011 where he contributed to the elaboration of teaching programs at the Higher Institute of Water Sciences and Technologies of Gabes. Since 2011, he has been lecturing at the Sfax National School of Engineering (University of Sfax, Tunisia). There, he has also been involved in various research projects related to Environmental Geology and Environmental Geotechnics. In addition, Dr. Kallel is involved as a consultant in urban and environmental projects for the Ministry of Environment and Sustainable Development in Tunisia. Dr. Kallel has organized many prestigious workshops, seminars and international conferences. Currently, he is supporting the editorial board of the Euro-Mediterranean Journal for Environmental Integration (Springer). In 2016 Dr. Kallel joined the AJGS as an Assistant Editor supporting the Editor-in-Chief.

\footnotetext{
A. Kallel $(\bowtie)$

Sfax National School of Engineering (ENIS),

University of Sfax, Sfax, Tunisia

e-mail: amjad.kallel@enis.tn
} 